GUEST EDITORIAL

\title{
Music and the brain: a heartland of psychiatry?
}

\author{
John Cox
}

Professor Emeritus, Keele University, UK; Past President, Royal College of Psychiatrists; Former Secret Former Secretary General, World email john1.cox@virgin.net

Declaration of interest. The author is a trustee of the Musical author is
Brain.
Music pervades our societies. We hear it in the dentist's waiting room, we half listen to it as we follow the chase in a wildlife programme, it stirs our emotions and can make us cry, and is often intimately associated with spiritual and religious practices. For some doctors it provides a creative space - a break from the world of target-driven technologies and top-down management systems. It is remembered, and can itself provoke memories that are emotionally laden and poignant (Ginsborg, 2016). The shared experience of performing or listening to music can be beneficial to health and well-being, and is used to facilitate the rehabilitation of patients with neuropsychiatric conditions and mood disorders, and as an aid to post-operative recovery (Glasziou, 2015; Hole et $a l, 2015)$. The nature of these positive musical experiences, the neural networks and central brain structures involved in their expression are beginning to be better understood.

This issue presents three papers on the theme of music therapy for neuropsychiatric conditions, collectively authored by two neuroscientists (Michael Trimble and Shantala Hegde), an epidemiologist (Dale Hesdorffer) and two music psychologists (Raluca Matei and Jane Ginsborg). They discuss aspects of the musical brain from different global and professional perspectives. The papers succinctly review selected evidence for the effectiveness of music therapy and highlight the modalities of South Asian music. They may also encourage psychiatrists to understand the importance of the global health humanities (Stewart \& Swain, 2016) and to reflect on their own professional development (Downie, 2016). Importantly, they familiarise readers with both the brain infrastructure of musical experience and its relevance to the management of some patients with mood disorder and performance anxiety.

\section{Empathic process}

Our increased knowledge of the cognitive processes of musical appreciation (how music is remembered, what emotions are aroused, how a sound is communicated to others), as well as the discovery of mirror neurons (Overy \& Molnar-Szakacs, 2009), which facilitate empathic communication, suggests that musical expression is a complex process rooted in the biosocial nature of personhood. From the sound to the experience, the mind-brain interface of musical appreciation is inherently interpersonal (Cox, 2011).

The extent to which these higher brain/mind processes direct neural plasticity and influence genetic expression is a key consideration at the present time. It is possible, as suggested by Trimble
\& Hesdorffer, that the influence of mind over matter has evolutionary importance. The human capacity to interpret and enjoy pitch and rhythm as well as harmony is rooted in cultural and evolutionary history - and passed on in infancy. We may have been lulled to sleep by the slow rhythm of a lullaby at the beginning of life (Friedman et al, 2010) and later consoled by memories of a loved one, heightened by the music of a requiem mass.

Listening to music, as well as performing, are not isolated individual activities but part of a dyadic or group experience, during which empathic processes operate - and a wave of feelings may pass through an attentive audience. The conductor of an orchestra conveys a musical phrase and its attached emotion through gesture (kinaesthetic empathy) as well as by eliciting a particular quality of sound from the orchestra. It is likely that music, because of its meaning, pitch, rhythm and cadence, preceded speech as a more primal form of human communication.

Yet knowledge of how the brain processes and communicates this musical language is in its infancy - and the answers are unlikely to be found in the neurosciences alone (Clarke \& Clarke, 2011). What happens to the vocal apparatus (larynx, tongue, lips and resonating sinuses) when we use the voice provides vivid functional magnetic resonance images of moving body parts and of brain localisation (Carey \& McGettigan, 2016) but these visualisations alone do not answer the question 'Why sing?'

\section{Other cultures}

Many Asian cultures, and in particular the Indian classical music tradition described by Shantala Hegde, have recognised the overlapping boundaries between meditative states, such as vipassana meditation and mindfulness, and an understanding of consciousness and of transcendence. The cadences of the ragas, she maintains, are rich in their ability to convey human emotion.

The Veda inspired Gustav Holst, for example, to search for the music of the spheres in his suite 'The Planets' - and he composed the 'Rig Veda' to give musical expression to the transcendence of the Upanishads. The Old Testament has images of exiled sojourners singing songs in strange lands (Psalm 137) and the procession of the Ark of God being carried to Jerusalem was led by a director of singing. African rhythms and dance are core components of healing practices. Mbiti (1990, p. 67), in his seminal book African Religions and Philosophy, states that music, singing and dancing 'reach deep into the innermost part of African peoples'. The chanting of the Imam at dawn is a rhythmic 
vocalised call to prayer and has a profound meaning for Muslims. Music is deeply embedded in our understanding of the world and hence in the understanding of patients as persons.

\section{Relevance for psychiatry}

Music is also embedded in the history and practice of psychiatry (Rollin, 1998). Many asylums had concert halls with orchestra and choir; Elgar conducted the Powick Asylum band and composed music for their concerts. Psychiatrists are consulted by musicians with mental disorders that impair their work and performance, as reported by Matei \& Ginsborg in this issue. Severe stress adversely affects the singer's voice and the violinist's intonation and can impair their livelihood. Temporal lobe epilepsy may present with musical hallucinations, and a stroke may be followed by amusia.

For some psychiatrists, however, music making is primarily a regenerating leisure activity that provides self-agency within an interpersonal space. For others (such as Anthony Storr, Felix Post, Michael Trimble and John Cordingly) their musical interest is expressed through their books. The Royal College of Psychiatrists celebrated the millennium with a Festival of Psychiatry and the Arts, with commissioned vocal music, dance, theatre and an exhibition by the psychoanalyst Ismond Rosen. The art and science of psychiatry were in juxtaposition: a blend of intuition, connectivity and natural science which is at the heart of musical appreciation - and very close to the heartland of psychiatry.
The triad of papers in this issue encourage readers to understand the universal and personal aspects of the musical brain and the musical mind and will, it is hoped, also enhance clinical practice.

\section{References}

Carey, D. \& McGettigan, C. (2016) Magnetic resonance imaging of the brain and vocal tract. Applications to the study of speech production and language learning. Neuropsychologia. https://doi. org/10.1016/j.neuropsychologia.2016.06.003. [Epub ahead of print]

Clarke, D. \& Clarke, E. (eds) (2011) Music and Consciousness: Philosophical, Psychological, and Cultural Perspectives. Oxford University Press.

Cox, J. L. (2011) Empathy, the song and the singer: the legacy of Robert Schumann. Advances in Psychiatric Treatment, 17, 447-458.

Downie, R. (2016) Medical humanities. Journal of the Royal College of Physicians of Edinburgh, 46, 288-294.

Friedman, S. H., Kaplan, R. S., Rosenthal, M. B., et al (2010) Music therapy in perinatal psychiatry: use of lullabies for pregnant and postpartum women with mental illness. Music and Medicine, 2, 219-225.

Ginsborg, J. (2016) Memory in music hearing, listening and performance. In Performing the Remembered Present: The Cognition of Memory in Dance Theatre and Music (ed. P. Hansen), ch. 7. Methuen.

Glasziou, P. (2015) Music in hospital. Lancet, 386, 1609-1610.

Hole, J., Hirsch, M., Ball, E., et al (2015) Music as an aid for postoperative recovery in adults: systematic review and metaanalysis. Lancet, 386, 1659-1671.

Mbiti, J. S. (1990) African Religions and Philosophy (2nd edn). Heinemann.

Overy, K. \& Molnar-Szakacs, I. (2009) Being together in time: musical experience and the mirror neuron system. Music Perception, 26, 489-504

Rollin, H. (1998) Pioneers of music therapy. Journal of Medical Biography, 6, 160-165.

Stewart, K. A. \& Swain, K. K. (2016) Global health humanities: defining an emerging field. Lancet, 388, 2586-2587.

\section{THEMATIC PAPER}

\title{
Music and the brain: the neuroscience of music and musical appreciation
}

\author{
Michael Trimble ${ }^{1}$ and Dale Hesdorffer ${ }^{2}$
}

${ }^{1}$ Institute of Neurology, University College London, UK email mtrimble@ion.ucl.ac.uk ${ }^{2}$ Gertrude H. Sergievsky Center and Department of Epidemilogy, Columbia University, New York City, USA
Through music we can learn much about our human origins and the human brain. Music is a potential method of therapy and a means of accessing and stimulating specific cerebral circuits. There is also an association between musical creativity and psychopathology. This paper provides a brief review.

Art history is the unfolding of subjectivity.... (T. Adorno)

\section{An evolutionary perspective}

There have been many attempts to identify behaviours which reliably distinguish our species, Homo sapiens, from our closest living cousins. Ascribed activities, from tool-making to having a theory of mind and empathy, have been rejected, as observations of anthropologists and ethnologists continue to emphasise similarities rather than differences placing us within the great chain of beings. There can be no doubt about the greater development of our cognitive attributes, linked closely with the evolutionary developments of our brain, in terms of both size and structure. Bipedalism, the use of fire, the development of effective working memory and our vocal language efficient communication have all emerged from these genetic-environmental adaptations over several million years (Pasternak, 2007).

Two features of our world which are universal and arguably have been a feature of an earlier 